\title{
Clinical and histopathological correlation: A study on 334 eyes with retinoblastoma from Vietnam
}

\author{
Ha Nguyen Ngan ${ }^{1,2,6}$, Van Pham Trong ${ }^{1,2}$, Tuan Hoang Anh ${ }^{3}$, Van Pham \\ Hong $^{2}$, Chung Nguyen Ngoc ${ }^{1,4}$, Tinh Nguyen Xuan ${ }^{5}$, Thuy Vu Thi Bich ${ }^{5}$, \\ R. Max Conway 6,7 \\ ${ }^{1}$ Department of Ophthalmology, Hanoi Medical University, Hanoi, Vietnam; \\ ${ }^{2}$ Department of Oculoplastics and Cosmesis, Vietnam National Institute of \\ Ophthalmology, Hanoi, Vietnam; ${ }^{3}$ Department of Histopathology, Vietnam \\ National Institute of Ophthalmology, Hanoi, Vietnam; ${ }^{4}$ Department of \\ Ophthalmology, Vietnam National Institute of Pediatrics, Hanoi, Vietnam; \\ ${ }^{5}$ Department of Pediatric Ophthalmology, Vietnam National Institute of \\ Ophthalmology, Hanoi, Vietnam; '5ave Sight Institute/Sydney Eye Hospital, The \\ University of Sydney, Sydney, NSW, Australia; ${ }^{7}$ St Vincent's Hospital, Sydney, NSW, \\ Australia
}

\begin{abstract}
Purpose: To elucidate the clinical features which predict high-risk histopathological factors for subsequent metastatic disease as well as to report the incidence of these highrisk histopathological factors in a cohort of Asian patients with retinoblastoma.

Design: A retrospective and non-randomized sequential cases series.

Methods: A retrospective study was done on 334 eyes with retinoblastoma at Vietnam National Institute of Ophthalmology during a ten-year period (January 2004 - December 2013). All pathology specimens and medical records were reviewed and assessed for invasion and clinical signs.

Results: Among 334 eyes, 225 (67.4\%) had high-risk retinoblastoma and 109 (22.6\%) had non-high-risk features on histopathology. The high-risk histopathological features included anterior chamber seeding (48.2\%), iris infiltration (14.7\%), ciliary body involvement (14.1\%), massive choroidal invasion (29.9\%), post-laminar optic nerve invasion (21.2\%), optic nerve margin involvement (9.6\%), combined choroidal and optic nerve invasion (9.6\%), scleral invasion (3.3\%), and extra-scleral infiltration (11.4\%). The significant clinical features in the high-risk group versus the non-high-risk group included hyphema $(19.6 \%$ vs $3.7 \%, p<0.001)$, pseudohypopyon $(19.1 \%$ vs $6.4 \%, p=0.001)$, iris neovascularization $(25.3 \%$ vs $5.5 \%, p<0.001)$, vitreous seeding $(72.4 \%$ vs $37.6 \%, p<$ $0.001)$, staphyloma ( $24 \%$ vs $4.6 \%, p<0.001)$ and scleritis ( $20 \%$ vs $3.7 \%, p<0.001)$.

Conclusions: Clinical signs including hyphema, pseudohypopyon, iris neovascularization, vitreous seeding, staphyloma and scleritis were significantly associated with highrisk features on histopathology. Globe preserving methods should be used with caution in patients with these signs.
\end{abstract}

Keywords: Retinoblastoma, clinical, histopathological, high-risk

Correspondence: Ha Nguyen Ngan, Department of Oculoplastic and Cosmesis, Vietnam National Institute of Ophthalmology, 85 Ba Trieu street, Hai Ba Trung district, Hanoi city, Vietnam.

E-mail: dr.nganha@gmail.com 


\section{Introduction}

Retinoblastoma $(\mathrm{Rb})$ is the most common malignant intraocular tumor in children with an incidence of one in 15000-20000 live births. ${ }^{1}$ In developed countries, the cure rate for children with $\mathrm{Rb}$ is greater than $95 \% .^{2}$ However, the success rate is limited to less than $50 \%$ in developing countries because of late diagnosis and insufficient treatment. ${ }^{3}$ The use of adjuvant chemotherapy after enucleation has been associated with increased survival of patients at risk of metastasis. Studies have shown that histopathologic factors may predict high-risk metastatic tumors. Those can be listed as anterior chamber seeding, iris invasion, ciliary body infiltration, massive choroidal infiltration, post-laminar optic nerve invasion, optic nerve margin involvement, combined choroidal and optic nerve infiltration, and sclera/ extra-scleral invasion. ${ }^{4-6}$

In this study, we elucidate the clinical features which predict high-risk histopathological factors (HRFs) for subsequent metastatic disease as well as to report the incidence of these HRFs in a cohort of 334 eyes from Asian patients primarily enucleated for $\mathrm{Rb}$. This research was performed at the Vietnam National Institute of Ophthalmology, which is a national treatment center for patients with $\mathrm{Rb}$ from the North of Vietnam, representing one third of the national population (93.39 million people).

\section{Methods}

This was a retrospective and non-randomized sequential case series. The study included all eyes with clinical retinoblastoma signs which have been primarily enucleated and pathologically confirmed during a ten-year period (January 2004 - December 2013).

Histopathological specimens were reviewed and grouped as high-risk and non-high-risk for subsequent metastatic disease. ${ }^{4-6}$ High-risk features on histopathology were defined as the presence of anterior segment involvement (including anterior chamber seeding, infiltration of iris or ciliary body) (Fig. 1), massive ( $\geq 3$ $\mathrm{mm}$ ) choroidal invasion, post-laminar optic nerve invasion, optic nerve margin involvement, combined non-massive choroidal and prelaminar/laminar optic nerve invasion, or scleral/extra-scleral infiltration..$^{4-6}$ Choroid invasion was divided into three groups: no choroid invasion, focal choroid invasion (less than $3 \mathrm{~mm}$ in the maximum diameter (width or thickness) and without touching the sclera), and massive choroid invasion ( $3 \mathrm{~mm}$ or more in maximal diameter; width or thickness and/or touches the inner surface of the sclera) (Fig. 2). Extent of optic nerve invasion was divided into four groups: no optic nerve invasion, pre-laminar or laminar optic nerve invasion, post-laminar optic nerve invasion, and optic nerve transection (Fig. 3).

Tumor growth pattern was also recorded. Exophytic growth was defined as tumor growing outwards from the outer surface of the retina into the sub-retinal space toward the choroid. Endophytic growth was defined as tumor growing towards the vitreous cavity. Some lesions demonstrated a combined endophytic-exophytic 


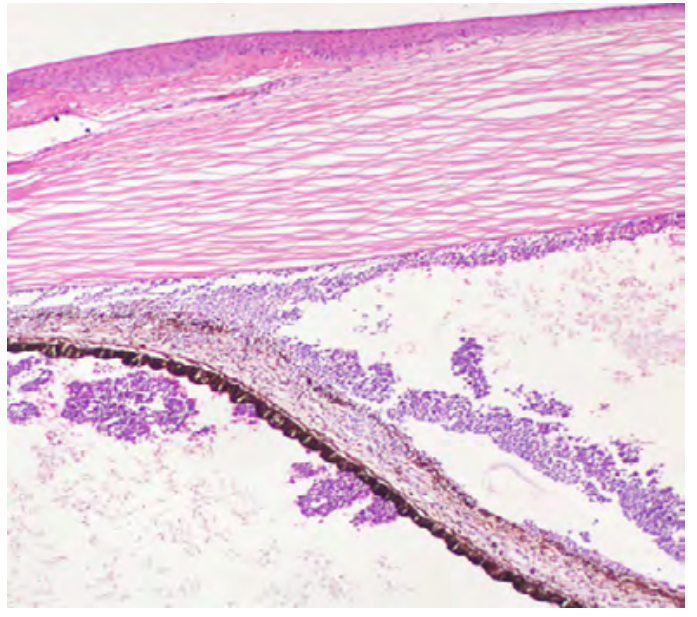

Fig. 1. Anterior segment invasion (HE stain, $\mathbf{x} 40)$.
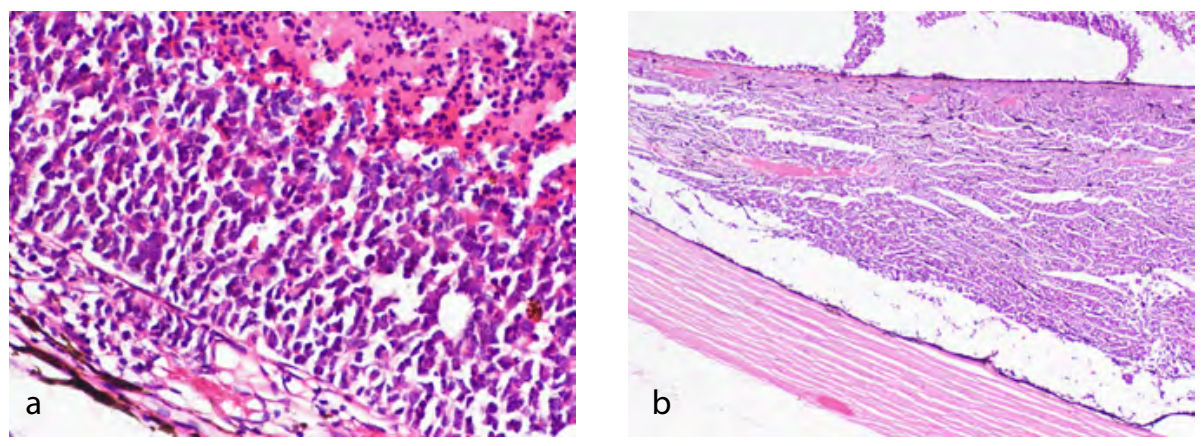

Fig. 2. Choroidal invasion. a (left). Focal choroidal invasion (HE stain, $x 100$ ); $b$ (right). Massive choroidal invasion (HE stain, $\mathrm{x40}$ ).

pattern. Tumors were divided into two groups according to differentiation: differentiated and undifferentiated. Tumor differentiation was defined as appearance of with Flexner-Wintersteiner rosettes and/or fleurettes. ${ }^{7}$ Tumor necrosis, calcification, and length of optic nerve were also noted.

Medical records were collected to review demographic and clinical signs. The demographic data included age at diagnosis (months), gender, hereditary pattern (sporadic or familial), and laterality. The clinical data included symptoms, intraocular pressure, hyphema, pseudohypopyon, dilated pupil, iris neovascularization, cataract, vitreous seeding, staphyloma, buphthalmos, phthisis bulbi, and scleritis at presentation.

\section{Statistical analyses}

Statistical analyses were performed using STATA 10.0 software. The Chi-square and Fisher's exact test were used to compare the qualitative data. A multivariate logistic-regression analysis was performed to identify the clinical predictors of HRFs on histopathology. 

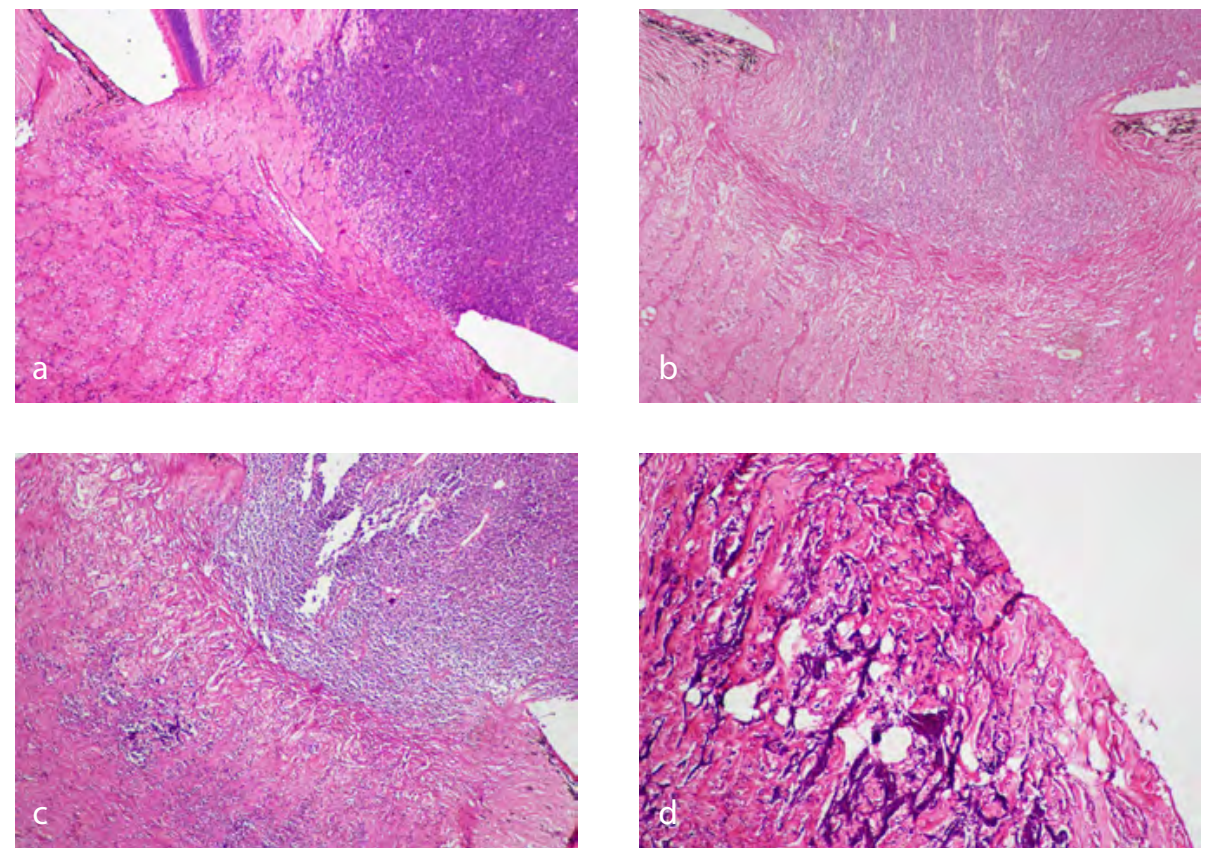

Fig.3. Optic nerve invasion (HE stain, $x 40$ ). a. Prelaminar optic nerve invasion; $b$. Laminar optic nerve invasion; c. Poslaminar optic nerve invasion; $d$. Invasion of optic nerve transection.

\section{Results}

\section{Basic demographics and clinical features}

Overall, the median age of patients at diagnosis was $25.44 \pm 15.84$ months ( 25.56 \pm 15.72 in high-risk versus $25.3 \pm 15.36$ months in non-high-risk group). Unilateral tumors were present in $80.5 \%$ of patients and bilateral disease was present in $19.5 \%$. In the unilateral group, the right eye was involved in $54.7 \%$ cases and the left in $45.3 \%$ cases. Male/female ratio was $1.2: 1$. Ten patients (3.3\%) had positive family history (eight in high-risk and two in non-high-risk group). All patients were of Asian racial background.

Leukocoria was the most common presenting symptoms in both groups, followed by decreased vision and strabismus. In medical consultation, vitreous seeding, staphyloma, and neovascularization iris are the most common clinical signs (Table 1).

\section{Histopathological features}

Histopathology details were available for all 334 primary enucleated globes. Of these 334 eyes, 225 (67.4\%) had high-risk and 109 (32.6\%) had non-high-risk features on histopathology.

Among high-risk cases, 101 (44.9\%) eyes had one high-risk factor, 52 (23.1\%) eyes 
had two factors and 72 (32\%) eyes had more than three factors. The histopathological high-risk features in these eyes included anterior chamber seeding $(n=$ $161,48.2 \%)$, iris infiltration ( $n=49,14.7 \%)$, ciliary body involvement $(n=47,14.1 \%)$, massive choroidal invasion $(n=100,29.9 \%)$, post-laminar optic nerve invasion ( $n$ $=71,21.2 \%)$, optic nerve margin involvement $(n=32,9.6 \%)$, combined choroidal and optic nerve invasion $(n=32,9.6 \%)$, scleral invasion $(n=11,3.3 \%)$, and extrascleral infiltration $(n=38,11.4 \%)$. Among cases with microscopic residual disease, $32(9.6 \%)$ involved optic nerve margin, $38(11.4 \%)$ had extra-scleral soft tissue invasion. Length of optic nerve was about $5-8 \mathrm{~cm}$ in $71 \%$ cases. The data details are shown in Table 2.

There was no statistical difference between the proportion of tumor necrosis, tumor thickness, exophytic tumor and endophytic tumor in eyes with high risk compared to that in eyes without high risk features. The median tumor thickness was $15.89 \mathrm{~mm}$ in the high-risk group and $12.55 \mathrm{~mm}$ in the non-high-risk group. Overall, 155 of 334 cases (46.4\%) had tumor calcification; corresponding figures in the high-risk and non-high-risk groups were 114 (50.7\%) and 41 (37.6\%), respectively. The rate of differentiated tumor was $48.9 \%(n=110)$ for the high-risk group versus $41.3 \%(n=45)$ for the non-high-risk group. Combined endophytic-exophytic growth presented in $78.7 \%(n=177)$ versus $44.0 \%(n=48)$ of eyes in high-risk and non high-risk cases, respectively (Table 1 ).

\section{Correlation between histopathological and clinical features}

The significant clinical features in the high-risk group versus non-high-risk group included hyphema $(19.6 \%$ vs $3.7 \%, p<0.001)$, pseudohypopyon $(19.1 \%$ vs $6.4 \%, p=$ $0.001)$, neovascularization iris ( $25.3 \%$ vs $5.5 \%, p<0.001)$, vitreous seeding $(72.4 \%$ vs $37.6 \%, \mathrm{p}<0.001)$, staphyloma ( $24 \%$ vs $4.6 \%, \mathrm{p}<0.001)$, and scleritis ( $20 \%$ vs $3.7 \%$, $\mathrm{p}<0.001$ ) (Table 1).

Clinical features that predict for individual histopathological high-risk factors are shown in Table 3. According to the collected data, clinical predictors for massive choroidal invasion included age more than two years at presentation, iris neovascularization, vitreous seeding, and buphthalmos. Age more than two years, staphyloma and cataract were significantly associated with post-laminar optic nerve invasion.

\section{Discussion}

There are three centers managing patients with $\mathrm{Rb}$ in Vietnam. This research was performed only at Vietnam National Institute of Ophthalmology, where children with $\mathrm{Rb}$ from the North of Vietnam were treated. Therefore, the study did not describe the whole picture of $\mathrm{Rb}$ in the country. Moreover, the absence of data on metastasis was also a limitation of this study. The study spanned ten years and 334 cases of $\mathrm{Rb}$ were reviewed. We included only primarily enucleated eyes and so the incidence of HRFs reported in our study represents the risk for metastasis in $\mathrm{Rb}$ at presentation unaffected by the effects of conservative interventions such as chemotherapy and laser. The mean age at diagnosis was $25.44 \pm 15.84$ months, 
which was similar to other studies in developing countries, ${ }^{8-10}$ but higher compared to those from the West. ${ }^{11}$ Detecting high-risk features on histopathology is necessary because untreated high-risk retinoblastoma has a risk of systemic metastasis in $24 \%$ of patients and adjuvant chemotherapy reduces the risk to $0 \%-4 \% .^{12,13}$

In previous studies, the incidence of HRF cases varied from $18.5 \%$ to $41.4 \%, 4,5,14-17$ In the current study, $67.4 \%$ cases had high-risk factors (Table 4 ). This has been attributed to a delay in presentation or diagnosis, which might be related to insufficient public awareness, lack of infant screening programs, and difficulties with access to medical services (e.g., long distances to travel to eye specialist services). Indeed we found it was not uncommon for some children with $\mathrm{Rb}$ to be taken to an herbalist instead of a hospital for primary treatment. Another issue we identified was artefact, which may have resulted in the significantly higher ratio of observed anterior segment invasion. Artefactual seeding is composed of small groups of tumor cells, usually with many necrotic cells present, inside natural spaces of the eye such as the anterior chamber. ${ }^{6}$ Artefacts may occur at different stages in the routine collection of the tissues, fixation, processing, cutting, and staining of tissues. Therefore, great care is needed at every stage in the preparation of histology slides in order to get an accurate result.

In our series of 334 eyes, the clinical features predictive of high-risk retinoblastoma included hyphema, pseudohypopyon, neovascularization iris, vitreous seeding, staphyloma, and scleritis. In an analysis of 403 patients by Kaliki et al., prolonged duration of symptoms of more than six months and secondary glaucoma might predict high-risk features on histopathology. ${ }^{14}$ In another study of 326 enucleated eyes by Kashyap et al., clinical predictors of high risk histopathology included age more than two years, lag period to diagnosis more than three months, hyphema, pseudohypopyon, staphyloma, and orbital cellulitis. ${ }^{15}$

In 2011, Kashyap et al. reported that predictors of post-laminar optic nerve invasion were older age at presentation, lag time to diagnosis greater than three months, and glaucoma. Meanwhile, predictors of massive choroidal invasion were cataract, staphyloma, and glaucoma. ${ }^{15}$ Further, Shields et al. had found that raised intraocular pressure (IOP) and neovascularization iris (NVI) were predictors of choroidal invasion, while raised IOP, exophytic growth pattern, and tumor thickness more than $15 \mathrm{~mm}$ predicted optic nerve invasion. ${ }^{18,19}$ In the current study, clinical predictors of massive choroidal invasion included age more than two years at presentation, neovascularization iris, vitreous seeding, and buphthalmos. Other signs such as age more than two years, staphyloma, and cataract were significantly associated with post-laminar optic nerve invasion.

In Northern Vietnam, the number of children presenting to our catchment center with $\mathrm{Rb}$ appears to be increasing (personal communication: hospital statistics since 2004). However, the management of these patients has been insufficient. Definitive diagnosis has relied upon detection of calcification using ultrasound and CT scan. MRI was rarely used to evaluate tumor invading eye structures. Lack of chemotherapy before and after enucleation may be associated with a poorer prognosis and increased mortality rate. Small tumors are particularly challenging, 
as brachytherapy plaques and transpupillary thermo-therapy (TTT) are currently not available. Genetic analysis has not been a routine practice which made counselling and early diagnosis by screening nearly impossible. Additionally, there is currently no rehabilitation program available in this country, which is especially significant. Enucleations are generally performed without implant with resulting orbital deformity. Until recently, no telemedicine or tumor board meeting has been available to develop a multidisciplinary approach to retinoblastoma management in Vietnamese patients. With the advent of better information technologies at reduced cost, we are currently piloting a telemedicine approach through the Sydney Multidisciplinary Ocular Oncology MDT.

\section{Conclusion}

This is a retrospective clinico-pathological analysis of a large number of Asian eyes from Vietnam after primary enucleation for Rb. In our study, clinical signs including hyphema, pseudohypopyon, iris neovascularization, vitreous seeding, staphyloma and scleritis were predictors of high-risk features for metastasis on histopathology. Knowledge of these clinical correlates embedded within the framework of applying the formal international staging criteria ${ }^{20}$ will assist ophthalmologists to better stratify patients to the most appropriate treatments, as these become available. These data suggest that within the context of current health care constraints within Vietnam; globe preserving methods should be used with caution in patients with these signs.

\section{Conflict of interest}

The authors declare that they have no conflict of interest.

\section{References}

1. Shields JA, Shields CL. Retinoblastoma. Intraocular tumors: an atlas and textbook. 2nd ed., pp. 294-318. USA: Lippincott Williams \& Wilkins 2007.

2. MacCarthy A, Birch J, Draper G, et al. Retinoblastoma: treatment and survival in Great Britain 1963 to 2002. Br J Ophthalmol 2009;93(1):38-39.

3. Bowman R, Mafwiri M, Luthert P, Luande J, Wood M. Outcome of retinoblastoma in east Africa. Pediatr Blood Cancer 2008;50(1):160-162.

4. Kaliki S, Shields CL, Rojanaporn D, et al. High-risk retinoblastoma based on international classification of retinoblastoma: analysis of 519 enucleated eyes. Ophthalmology 2013;120(5):997-1003.

5. Kashyap S, Sethi S, Meel R, et al. A histopathologic analysis of eyes primarily enucleated for advanced intraocular retinoblastoma from a developing country. Arch Pathol Lab Med 2012;136(2):190.

6. Sastre X, Chantada GL, Doz F, et al. Proceedings of the consensus meetings from the International Retinoblastoma Staging Working Group on the pathology guidelines for the examination of enucleated eyes and evaluation of prognostic risk factors in retinoblastoma. Arch Pathol Lab Med 2009;133(8):1199.

7. Grossniklaus HE, Kivëla T, Harbour JW, Finger PT. Protocol for the examination of specimens from patients with retinoblastoma. Based on AJCC/UICC TNM. 7th ed. Northfield, IL: College of American Pathologists 2013. 
8. Nabie R, Taheri N, Fard AM, Fouladi RF. Characteristics and clinical presentations of pediatric retinoblastoma in North-western Iran. Int J Ophthalmol 2012;5(4):510.

9. Kazadi Lukusa A, Aloni MN, Kadima-Tshimanga B, et al. Retinoblastoma in the democratic republic of congo: 20-year review from a tertiary hospital in kinshasa. J Cancer Epidemiol 2012.

10. Meel R, Radhakrishnan V, Bakhshi S. Current therapy and recent advances in the management of retinoblastoma. Indian J Med Paed Oncol 2012;33(2):80.

11. da Rocha-Bastos $R$, Araújo J, Silva $R$, et al. retinoblastoma: experience of a referral center in the north region of Portugal. Clin Ophthalmol (Auckland, NZ) 2014;8:993.

12. Honavar SG, Singh $A D$, Shields $C L$, et al. Postenucleation adjuvant therapy in high-risk retinoblastoma. Arch Ophthalmol 2002;120(7):923-931.

13. Kaliki S, Shields CL, Shah SU, Eagle RC, Shields JA, Leahey A. Postenucleation adjuvant chemotherapy with vincristine, etoposide, and carboplatin for the treatment of high-risk retinoblastoma. Arch Ophthalmol 2011;129(11):1422-1427.

14. Kaliki S, Srinivasan V, Gupta A, Mishra DK, Naik MN. Clinical Features Predictive of High-Risk Retinoblastoma in 403 Asian Indian Patients: A Case-Control Study. Ophthalmology 2015;122(6):1165-1172.

15. Kashyap S, Meel R, Pushker N, et al. Clinical predictors of high risk histopathology in retinoblastoma. Pediatr Blood Cancer 2012;58(3):356-361.

16. Yousef YA, Hajja Y, Nawaiseh I, et al. A Histopathologic Analysis of 50 Eyes Primarily Enucleated for Retinoblastoma in a Tertiary Cancer Center in Jordan/Ürdün'de Üçüncü Basamak Kanser Merkezinde Retinoblastoma Nedeniyle Primer Enükleasyon Uygulanan 50 Gözün Histopatolojik İncelemesi. Turk J Pathol 2014;30(3):171-177.

17. Eagle Jr RC. High-risk features and tumor differentiation in retinoblastoma: a retrospective histopathologic study. Arch Pathol Lab Med 2009;133(8):1203.

18. Shields CL, Shields JA, Baez K, Cater JR, de Potter P. Optic nerve invasion of retinoblastoma. Metastatic potential and clinical risk factors. Cancer 1994;73(3):692-698.

19. Shields CL, Shields JA, Baez KA, Cater J, De Potter PV. Choroidal invasion of retinoblastoma: metastatic potential and clinical risk factors. Br J Ophthalmol 1993;77(9):544-548.

20. Shields $\mathrm{CL}$, Shields JA. Basic understanding of current classification and management of retinoblastoma. Curr Opin Ophthalmol 2006;17(3):228-234. 
Ngan, Trong, Anh, et al.

\section{Tables}

Table 1. Clinical features of 334 eyes with retinoblastoma.

\begin{tabular}{|c|c|c|c|c|c|}
\hline \multicolumn{2}{|c|}{$\begin{array}{l}\text { Clinical and histopathological } \\
\text { features }\end{array}$} & $\begin{array}{c}\text { All eyes } \\
n=334, n \\
(\%)\end{array}$ & $\begin{array}{l}\text { High-risk } \\
n=225, \mathrm{n} \\
(\%)\end{array}$ & $\begin{array}{c}\text { Non-high-risk } \\
\begin{array}{c}n=109, \mathbf{n} \\
(\%)\end{array}\end{array}$ & $\mathbf{P}$ \\
\hline \multicolumn{2}{|l|}{ Leukocoria } & $280(83.8)$ & $191(84.9)$ & $89(81.7)$ & 0.16 \\
\hline \multicolumn{2}{|c|}{ Decreased vision } & $48(14.4)$ & $32(14.2)$ & $16(14.7)$ & 0.91 \\
\hline \multicolumn{2}{|l|}{ Strabismus } & $42(12.6)$ & $28(12.4)$ & $14(12.8)$ & 0.92 \\
\hline \multicolumn{2}{|l|}{ Eye pain } & $20(6)$ & $13(5.8)$ & $7(6.4)$ & 0.82 \\
\hline \multicolumn{2}{|l|}{ Red eye } & $15(4.5)$ & $12(5.3)$ & $3(2.8)$ & 0.2 \\
\hline \multicolumn{2}{|l|}{ Proptosis } & $13(3.9)$ & $10(4.4)$ & $3(2.8)$ & 0.4 \\
\hline \multicolumn{2}{|l|}{ Hyphema } & $48(14.4)$ & $44(19.6)$ & $4(3.7)$ & 0.000 \\
\hline \multicolumn{2}{|c|}{ Pseudohypopyon } & $50(15)$ & $43(19.1)$ & $7(6.4)$ & 0.001 \\
\hline \multicolumn{2}{|l|}{ Dilated pupil } & $19(5.7)$ & $14(6.2)$ & $5(4.6)$ & 0.4 \\
\hline \multicolumn{2}{|c|}{ Iris neovascularization } & $63(18.9)$ & $57(25.3)$ & $6(5.5)$ & 0.000 \\
\hline \multicolumn{2}{|l|}{ Cataract } & $23(6.9)$ & $16(7.1)$ & $7(6.4)$ & 0.55 \\
\hline \multicolumn{2}{|l|}{ Vitreous seeding } & $204(61.1)$ & $163(72.4)$ & $41(37.6)$ & 0.000 \\
\hline \multicolumn{2}{|l|}{ Elevated IOP } & $18(5.4)$ & $15(6.7)$ & $3(2.8)$ & 0.1 \\
\hline \multicolumn{2}{|l|}{ Buphthalmos } & $20(6)$ & $15(6.7)$ & $5(4.6)$ & 0.5 \\
\hline \multicolumn{2}{|l|}{ Staphyloma } & $59(17.7)$ & $54(24)$ & $5(4.6)$ & 0.000 \\
\hline \multicolumn{2}{|l|}{ Scleritis } & $49(14.7)$ & $45(20)$ & $4(3.7)$ & 0.000 \\
\hline \multicolumn{2}{|l|}{ Phthisis bulbi } & $2(0.6)$ & $2(0.9)$ & $0(0)$ & - \\
\hline \multicolumn{2}{|c|}{ Tumor calcification } & $155(46.4)$ & $114(50.7)$ & $41(37.6)$ & 0.025 \\
\hline \multicolumn{2}{|l|}{ Tumor necrosis } & $297(88.9)$ & $202(89.8)$ & $95(87.2)$ & 0.47 \\
\hline \multicolumn{2}{|c|}{ Differentiated tumor } & $155(46.4)$ & $110(48.9)$ & $45(41.3)$ & 0.19 \\
\hline \multirow{3}{*}{$\begin{array}{l}\text { Tumor growth } \\
\text { pattern }\end{array}$} & Exophytic & $67(20.1)$ & 44 (19.6) & $23(21.1)$ & 0.74 \\
\hline & Endophytic & $42(12.6)$ & $30(13.3)$ & $12(11)$ & 0.55 \\
\hline & Combined & $225(67.4)$ & $177(78.7)$ & $48(44.0)$ & 0.000 \\
\hline
\end{tabular}


Table 2. Histopathological high-risk factors of 334 eyes with retinoblastoma.

\begin{tabular}{|c|c|c|c|}
\hline \multicolumn{2}{|c|}{ Histopathological features } & \multirow{2}{*}{$\begin{array}{c}\begin{array}{c}\text { Number } \\
\text { (eyes) }\end{array} \\
161\end{array}$} & \multirow{2}{*}{$\begin{array}{c}\begin{array}{c}\text { Percentage } \\
(\%)\end{array} \\
48.2\end{array}$} \\
\hline Anterior chamber & Anterior chamber tumor seeds & & \\
\hline & Iris invasion & 49 & 14.7 \\
\hline & Ciliary body invasion & 47 & 14.1 \\
\hline \multirow[t]{3}{*}{ Choroidal invasion } & No & 191 & 57.2 \\
\hline & Minor $(<3 \mathrm{~mm})$ & 43 & 12.9 \\
\hline & Massive $(\geq 3 \mathrm{~mm})$ & 100 & 29.9 \\
\hline \multirow[t]{3}{*}{ Scleral invasion } & No & 285 & 85.3 \\
\hline & Scleral infiltration & 11 & 3.3 \\
\hline & Extrascleral involment & 38 & 11.4 \\
\hline \multirow{5}{*}{$\begin{array}{l}\text { Optic nerve } \\
\text { infiltration }\end{array}$} & No & 48 & 14.4 \\
\hline & Prelaminar & 118 & 35.3 \\
\hline & Laminar & 65 & 19.5 \\
\hline & Postlaminar & 71 & 21.2 \\
\hline & Optic nerve margin involvement & 32 & 9.6 \\
\hline
\end{tabular}


Table 3. Clinical predictors of Individual Histopathological High Risk Features (Multivariable Analysis, OR and 95\% Cl)

\begin{tabular}{|c|c|c|c|c|c|c|c|c|}
\hline & $A C$ & Iris Invasion & $\begin{array}{l}\text { Ciliary body } \\
\text { invasion }\end{array}$ & $\begin{array}{l}\text { Massive } \\
\text { choroidal } \\
\text { invasion }\end{array}$ & $\begin{array}{l}\text { Scleral } \\
\text { invasion }\end{array}$ & $\begin{array}{l}\text { Post-laminar } \\
\text { ON invasion }\end{array}$ & $\begin{array}{l}\text { ON cut end } \\
\text { invasion }\end{array}$ & $\begin{array}{l}\text { Extra scleral } \\
\text { invasion }\end{array}$ \\
\hline Age $>2$ years & & & $\begin{array}{l}0.3 \\
(0.1-0.8)\end{array}$ & $\begin{array}{l}0.3 \\
(0.1-0.7)\end{array}$ & & $\begin{array}{l}0.7 \\
(0.3-0.9)\end{array}$ & $\begin{array}{l}1.6 \\
(1.1-4.5)\end{array}$ & \\
\hline Hyphema & $\begin{array}{l}2.7 \\
(1.2-48.7)\end{array}$ & $\begin{array}{l}2.8 \\
(1.1-89.8)\end{array}$ & $\begin{array}{l}2.9 \\
(1.1-130.7)\end{array}$ & & & & & \\
\hline Pseudohypopyon & & $\begin{array}{l}1.5 \\
(1.2-12.2)\end{array}$ & & & & & & \\
\hline Dilated pupil & & & $\begin{array}{l}3.5 \\
(1.1-11.2)\end{array}$ & & & & & \\
\hline Iris neovascularization & & $\begin{array}{l}0.03 \\
(0.00-0.3)\end{array}$ & & $\begin{array}{l}0.08 \\
(0.003-0.8)\end{array}$ & & & & \\
\hline Cataract & $\begin{array}{l}3.6 \\
(1.1-11.7)\end{array}$ & $\begin{array}{l}3.7 \\
(1.2-11.3)\end{array}$ & $\begin{array}{l}4.3 \\
(1.4-13.1)\end{array}$ & & & $\begin{array}{l}4.7 \\
(1.4-15.4)\end{array}$ & & \\
\hline Vitreous seeding & & & & $\begin{array}{l}1.3 \\
(1.2-3.3)\end{array}$ & & & & \\
\hline Elevated IOP & $\begin{array}{l}1,7 \\
(1.5-5.8)\end{array}$ & & & & & & & \\
\hline Buphthalmos & & $\begin{array}{l}5.4 \\
(1.6-18.8)\end{array}$ & $\begin{array}{l}6.0 \\
(1.6-22.5)\end{array}$ & $\begin{array}{l}17.3 \\
(3.6-82.3)\end{array}$ & & & $\begin{array}{l}11.1 \\
(2.4-53.7)\end{array}$ & $\begin{array}{l}12.7 \\
(3.2-49.6)\end{array}$ \\
\hline Staphyloma & & & & & $\begin{array}{l}5.1 \\
(1.7-37.9)\end{array}$ & $\begin{array}{l}1.8 \\
(1.3-12.4)\end{array}$ & & \\
\hline Scleritis & & & & & $\begin{array}{l}17.1 \\
(3.9-213.8)\end{array}$ & & & \\
\hline Phthisi bulbi & & & & & & & & \\
\hline
\end{tabular}


Table 4. Comparison of incidence (\%) of high risk factors in various reported series

\begin{tabular}{|c|c|c|c|c|c|c|c|c|c|c|c|c|}
\hline Author & Country & Year & $\begin{array}{l}\text { Number } \\
\text { of eyes }\end{array}$ & $\begin{array}{l}\text { Median } \\
\text { age ate } \\
\text { diagnosis } \\
\text { (months) }\end{array}$ & $\begin{array}{l}\text { AC } \\
\text { invasion }\end{array}$ & $\begin{array}{l}\text { Iris } \\
\text { invasion }\end{array}$ & $\begin{array}{l}\text { Ciliary } \\
\text { invasion }\end{array}$ & $\begin{array}{l}\text { Massive } \\
\text { choroidal } \\
\text { invasion }\end{array}$ & $\begin{array}{l}\text { Scleral } \\
\text { invasion }\end{array}$ & $\begin{array}{l}\text { Post } \\
\text { laminar ON } \\
\text { invasion }\end{array}$ & $\begin{array}{l}\text { ON cut } \\
\text { end } \\
\text { invasion }\end{array}$ & $\begin{array}{l}\text { Extrascleral } \\
\text { invasion }\end{array}$ \\
\hline Kaliki et al. ${ }^{14}$ & India & 2015 & 403 & 27 & 6 & 3 & 4 & 17 & 5 & 18 & 1 & 2 \\
\hline Yousef Y et al. ${ }^{16}$ & Jordan & 2014 & 50 & 30 & 14 & 28 & 6 & 18 & 0 & 14 & 0 & 0 \\
\hline Kashyap et al. ${ }^{5}$ & India & 2012 & 609 & 30 & 10 & 10.7 & 6.7 & 24.6 & 13.7 & 16.1 & 7.4 & 4.1 \\
\hline Kashyap et al. ${ }^{15}$ & India & 2012 & 326 & 24 & 7 & 9 & 7 & 22 & 9 & 17 & 5.5 & 3.4 \\
\hline Eagle et al. ${ }^{17}$ & US & 2009 & 387 & & 8 & & & 8.4 & & 10.4 & 0.3 & \\
\hline Current study & Vietnam & 2015 & 334 & 25.44 & 48.2 & 14.7 & 14.1 & 29.9 & 3.3 & 21.2 & 9.6 & 11.4 \\
\hline
\end{tabular}

